\title{
Dietary practices among Europeans and different South Asian groups in Coventry
}

\author{
BY DAVID SIMMONS ${ }^{1} *$ AND RHYS WILLIAMS ${ }^{2}$ \\ ${ }^{\mathrm{l}}$ Sheikh Rashid Diabetes Unit, Radcliffe Infirmary, Oxford OX2 $6 \mathrm{HE}$ \\ ${ }^{2}$ Nuffield Institute for Health, 7I-75 Clarendon Road, Leeds LS2 9PL
}

(Received 16 April 1996 - Revised 11 November 1996 - Accepted 6 January 1997)

\begin{abstract}
The dietary customs of people of South Asian origin living in Britain are important determinants of health but have been relatively little studied. As part of the Coventry study of diabetes carried out in the Foleshill ward of the city, subjects undergoing oral glucose tolerance tests provided information on this aspect of lifestyle. A questionnaire was completed by all of the last 612 subjects undergoing testing. These included 304 of European origin, 118 Punjabi Sikhs, seventy-six Pakistani/Punjabi Moslems, twenty-eight Gujerati Moslems, twenty-five Punjabi Hindus and forty-seven Gujerati Hindus. There were no discernible differences in the dietary customs of those with normal glucose tolerance, impaired glucose tolerance and newly diagnosed diabetes. Subjects of South Asian origin ate significantly fewer meals per day than European subjects. Evening meal times were $2-3 \mathrm{~h}$ later among South Asians. Europeans ate less fruit but more vegetables and more brown rice than South Asians. Gujeratis ate more rice, fried snacks and white flour. Moslems were least likely to be vegetarians, to drink alcohol and to use home-made ghee and yoghurt, and Punjabi Sikhs and Hindus ate dhal more frequently than Pakistani Moslems, Gujerati Moslems or Hindus. Most South Asians ate Indian sweets and 'Western' snacks.
\end{abstract}

Non-insulin-dependent diabetes: Diet: South Asians

South Asians have a high prevalence of non-insulin dependent diabetes mellitus (NIDDM) (Simmons et al. 1989) and initiatives are urgently required to reduce their incidence of NIDDM. Any community-based diabetes control programme to achieve this end would benefit from knowing the dietary customs of South Asians, including which members of the family to target for nutrition education and demonstrations. The dietary advice given to the South Asian diabetic patient follows the high-carbohydrate, high-fibre, low-fat recommendations from the British Diabetic Association (1992) with a tailoring to the particular cultural practices of the various South Asian regional and religious groups (Peterson \& Govindji, 1988).

Despite the importance of nutrition in the control of diabetes and body weight, there are few studies describing the dietary customs of the various South Asian groups in the UK. Dietary surveys have been among predominantly Gujerati Hindus and have showed high fat intake (particularly coming from ghee and cooking oils) in those with (Peterson et al. 1986; Samanta et al. 1987) and without (Stephens et al. 1982; McKeigue et al. 1985; Miller et al. 1988) diabetes. Many early studies in other South Asian groups focused on mineral and vitamin intake (Elwood et al. 1972; Stephens et al. 1982; Abraham et al. 1985; Ward et al. 1988). A qualitative description of meal patterns, food, shopping and cooking customs among Pakistani, Bangladeshi, Gujerati Hindu and Punjabi Sikh women attending

* Present address: Division of Medicine, Middlemore Hospital, Otahuhu, Auckland 6, New Zealand. 
Sorrento maternity hospital was carried out in Birmingham in 1982 (Wharton et al. 1983), but no other similar studies have been published.

We now compare the dietary customs of Europeans, Pakistanis, Gujerati Hindus and Moslems and Punjabi Sikhs and Hindus in Foleshill, Coventry, an area with a high proportion of South Asians and a high prevalence of NIDDM (Simmons et al. 1989).

\section{METHODS}

Foleshill is an electoral ward in the northern part of the city of Coventry and one of the most deprived electoral wards in England and Wales (Jarman, 1983). The area has a high proportion of South Asians who migrated to the city from Pakistan and Northern India in the early 1960s, or, later, from East Africa. A study team was recruited from the local population, half of whom were of Asian extraction. Team members, working in pairs, went house to house screening adult (age $\geq 20$ years) residents for diabetes. A population census occurred at the same time as these visits and houses were visited until at least one member of the household was seen. Where residents agreed to participate in the survey, a questionnaire was completed (including sex, age, religion, diabetes status, place of birth to three generations and time of last meal), the weight and height were taken and a capillary whole blood sample was collected. Region and religion of origin for South Asians were classified by grandparental origin.

Subjects with a high blood glucose concentration (a 'positive screen' : $\geq 5.0 \mathrm{mmol} / 1$ $2 \mathrm{~h}$ or more after a meal or $\geq 6.0 \mathrm{mmol} / 1$ within $2 \mathrm{~h}$ of a meal) and a randomly selected $10 \%$ of others (a 'negative screen') were invited to attend a second session where an oral glucose tolerance test (OGTT) was performed as previously described (Simmons et al. 1989). Capillary glucose concentration was analysed on an Analox GM5 glucose oxidase machine (Analox Ltd, London) (inter-assay CV $1.4 \%$ ). The diagnosis of diabetes and impaired glucose tolerance (IGT) followed World Health Organization (1985) recommendations. Prior diagnosis of diabetes was verified from general practitioner or hospital records. During the OGTT, subjects completed a questionnaire in their own language relating to domestic habits (e.g. who did the shopping and cooking) and to meal times ('How many times do you eat during the day? At about what times?'). These questions were added to the questionnaire 10 months after commencing the study. Those who were illiterate were assisted with the questionnaire by one of the survey team speaking the appropriate language.

\section{Statistics}

Statistics were calculated on a personal computer using Statistical Package for the Social Sciences for Windows (release 6.0, SPSS Inc., Chicago, IL, USA). All tests were twotailed. Continuous variables are shown as means with $95 \%$ confidence intervals adjusted for screening group, age and sex using multiple linear regression. Significance probabilities of differences between groups are also shown. Age-, sex- and screening group-adjusted frequencies of discreet variables were adjusted in proportion to the odds ratios and predicted frequency of the group with the highest odds ratio using logistic regression. These regressions also provided significance probability between ethnic groups and, within South Asians, in comparison with the reference group (Punjabi Sikhs).

Subjects came from 552 households and included ninety-six from forty-eight households with two subjects, and eighteen from six households with three subjects. To assess the impact of such clustering, all analyses were repeated including only one 
(randomly selected) subject from the over-represented households. In no instance was there a significant alteration in results. In view of this, results from the whole sample are shown. The study was approved by the Coventry Ethics Committee and the Local Medical Committee.

\section{RESULTS}

Of the 10304 adult residents of Foleshill, 3529 (64\%) Europeans and 3692 (72\%) Asians were seen, of whom 1114 Europeans and 1084 Asians without known diabetes were invited to the OGTT. Table 1 shows the characteristics of those with 'positive' and 'negative' screens. Seven-hundred and nineteen (65\%) Europeans and $780(72 \%)$ Asians attended. The domestic activities questionnaire was completed by all subjects after its introduction (304 (42\%) Europeans and 308 (39\%) South Asians). The South Asians included 118 Punjabi Sikhs, seventy-six Pakistani/Punjabi Moslems, twenty-eight Gujerati Moslems, twenty-five Punjabi Hindus and forty-seven Gujerati Hindus. There were no differences in the data collected between those attending the OGTT who did and did not complete the domestic habits questionnaire. There were no significant dietary differences between those with diagnosed NIDDM or IGT and other subjects.

Table 2 shows anthropometric measurements and the domestic activities by sex and ethnic group. South Asians were more likely to be living with their family, and ate fewer meals per day with more people at the dining table. Fig. 1 shows the proportion of subjects eating at each hour of the day by ethnic group. A higher proportion of Europeans than South Asians ate before 08.00 hours $(P<0.05)$, between 15.00 and 17.00 hours $(P<0.05)$ and between 17.00 and 19.00 hours $(P<0.001)$. A higher proportion of South Asians ate between 19.00 and 21.00 hours $(P<0.001)$. There were no significant differences in the reported domestic activities or meal times between the five major South Asian regionalreligious groups.

Tables 3 and 4 compare the dietary habits of the five South Asian groups. Regular fasting was more common among Pakistani and Gujerati Moslems and Gujerati Hindus than the other two groups $(P<0.001)$. Moslems (4\% and $9 \%$ respectively) were less likely to be vegetarian than Sikhs $(43 \%)$ or Hindus $(33 \%)(P<0.001)$ and ate vegetables less frequently $(P<0.001)$. Abstention from alcohol was most common among Moslems and least common among Hindus $(P<0.001)$. When compared with Sikhs (odds ratio set as 1.0), Gujerati Moslems and Hindus were more likely, and Punjabi Hindus less likely to use white rather than brown or wholemeal flour in their chapatis. Parathas were particularly eaten by Punjabi Hindus, and rarely eaten by Gujerati Moslems. There were no differences between South Asian groups in the proportion who ate rice (overall $85 \%$ at least once weekly). While there were no significant South Asian group differences in proportion eating brown rice, none of the Gujeratis (Moslem or Hindu) ate brown rice. Of those who ate rice, more Europeans ate brown rice $(9$ v. $2 \%, P<0.001)$.

Moslems were least likely to eat eggs but there were no differences between the South Asian groups in the methods for cooking eggs. Moslems were most likely, and Gujerati Hindus least likely to eat fish. The former were most likely to fry their fish. Very few South Asians had boiled or steamed fish, unlike Europeans who commonly reported these methods of preparation $(1 v .15 \%, P<0.001 ; 3 v .14 \%, P<0.001$ respectively).

There were no differences between groups in the proportion eating fried snacks (samosa, pakora, poori, sev, chevda; overall 70\%). Gujerati Moslems were least likely to use butter or ghee for cooking. Home-made ghee and yoghurt were most used by Gujerati Hindus and least by Pakistani Moslems. Paneer (a cheese-like food) was most eaten by Punjabis but was eaten by no Gujerati Moslems. Cheese was most eaten by Punjabi Hindus 


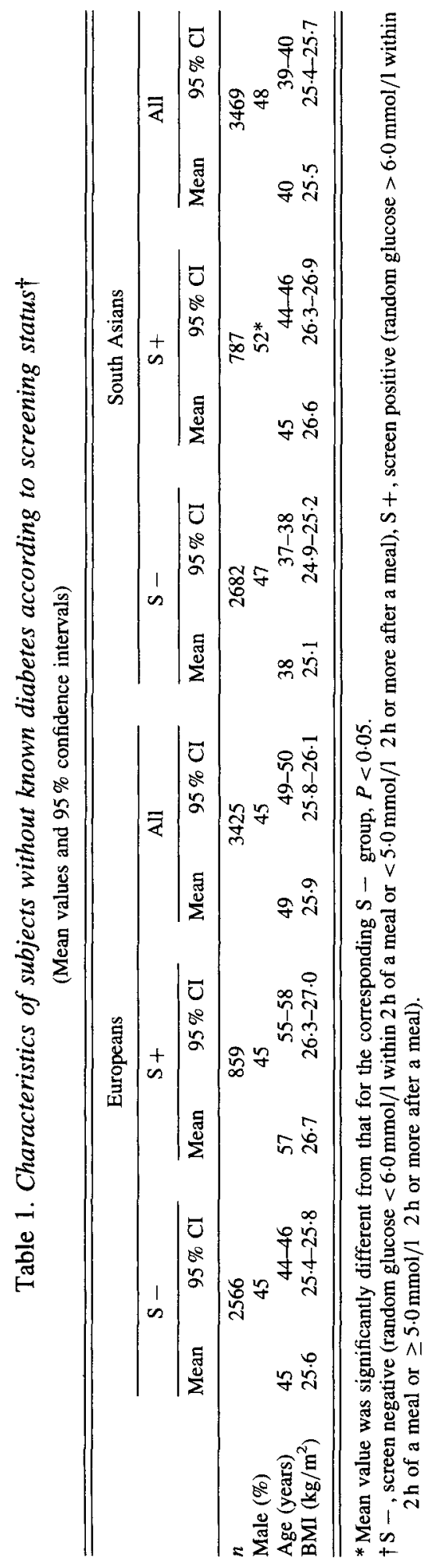


Table 2. Domestic activities of Foleshill European and South Asian men and women $\dagger$

(Mean values and $95 \%$ confidence intervals)

\begin{tabular}{|c|c|c|c|c|c|c|c|c|}
\hline & \multicolumn{2}{|c|}{ European men } & \multicolumn{2}{|c|}{ Asian men } & \multicolumn{2}{|c|}{ European women } & \multicolumn{2}{|c|}{ Asian women } \\
\hline & Mean & $95 \% \mathrm{CI}$ & Mean & $95 \% \mathrm{CI}$ & Mean & $95 \% \mathrm{CI}$ & Mean & $95 \% \mathrm{CI}$ \\
\hline$n$ & \multicolumn{2}{|r|}{30} & \multicolumn{2}{|c|}{161} & \multicolumn{2}{|c|}{174} & \multicolumn{2}{|c|}{147} \\
\hline Age (years) & 52 & $49-55$ & 44 & $42-47$ & 55 & $52-58$ & 42 & $40-44$ \\
\hline Weight (kg) & 77 & $75-80$ & 73 & $71-75$ & 65 & $63-67$ & 65 & $63-67$ \\
\hline Height (m) & 1.71 & $1.70-1.73$ & 1.68 & $1.67-1.69$ & 1.59 & $1.58-1.60$ & 1.55 & $1.54-1.56$ \\
\hline BMI $\left(\mathrm{kg} / \mathrm{m}^{2}\right)$ & $26 \cdot 3$ & $25 \cdot 5-27 \cdot 0$ & $25 \cdot 7$ & $24.9-26 \cdot 1$ & 25.8 & $24.9-26 \cdot 6$ & $27 \cdot 1$ & $26 \cdot 3-27.9$ \\
\hline $\begin{array}{l}\% \text { Living with } \\
\text { own family }\end{array}$ & 49 & & $90 * * *$ & & 57 & & $97 * * *$ & \\
\hline $\begin{array}{l}\text { No. eating } \\
\text { together at meal } \\
\text { times }\end{array}$ & 3 & $3-3$ & $5 * * *$ & $4-5$ & 3 & $2-3$ & $4 * * *$ & $3-4$ \\
\hline $\begin{array}{l}\text { No. of times eat } \\
\text { during the day }\end{array}$ & $3 \cdot 1$ & $3 \cdot 0-3 \cdot 3$ & 2.5 & $2 \cdot 4-2.6$ & 2.9 & $2 \cdot 8-3 \cdot 1$ & $2 \cdot 7$ & $2 \cdot 6-2 \cdot 9$ \\
\hline \multicolumn{9}{|l|}{$\begin{array}{l}\text { Who does the } \\
\text { cooking at home } \\
(\%) ? \ddagger\end{array}$} \\
\hline Spouse & 69 & & 79 & & 3 & & 3 & \\
\hline Self & 20 & & $10 * * *$ & & 97 & & 92 & \\
\hline \multicolumn{9}{|l|}{$\begin{array}{l}\text { Who does the } \\
\text { shopping at } \\
\text { home }(\%) ? \ddagger\end{array}$} \\
\hline Spouse & 43 & & 51 & & 14 & & 14 & \\
\hline Self & 57 & & 47 & & 86 & & $46^{* *}$ & \\
\hline
\end{tabular}

Mean values were significantly different from those for Europeans, within sex: $* P<0.05, * * P<0.01, * * * P<0.001$.

$\dagger$ Continuous data are shown as age- and screening-group-adjusted means and $95 \% \mathrm{CI}$ within sex; discrete data are shown as predicted frequencies after adjusting for age and screening group within sex by logistic regression.

$\ddagger$ Excludes others cooking and shopping, e.g. parents.

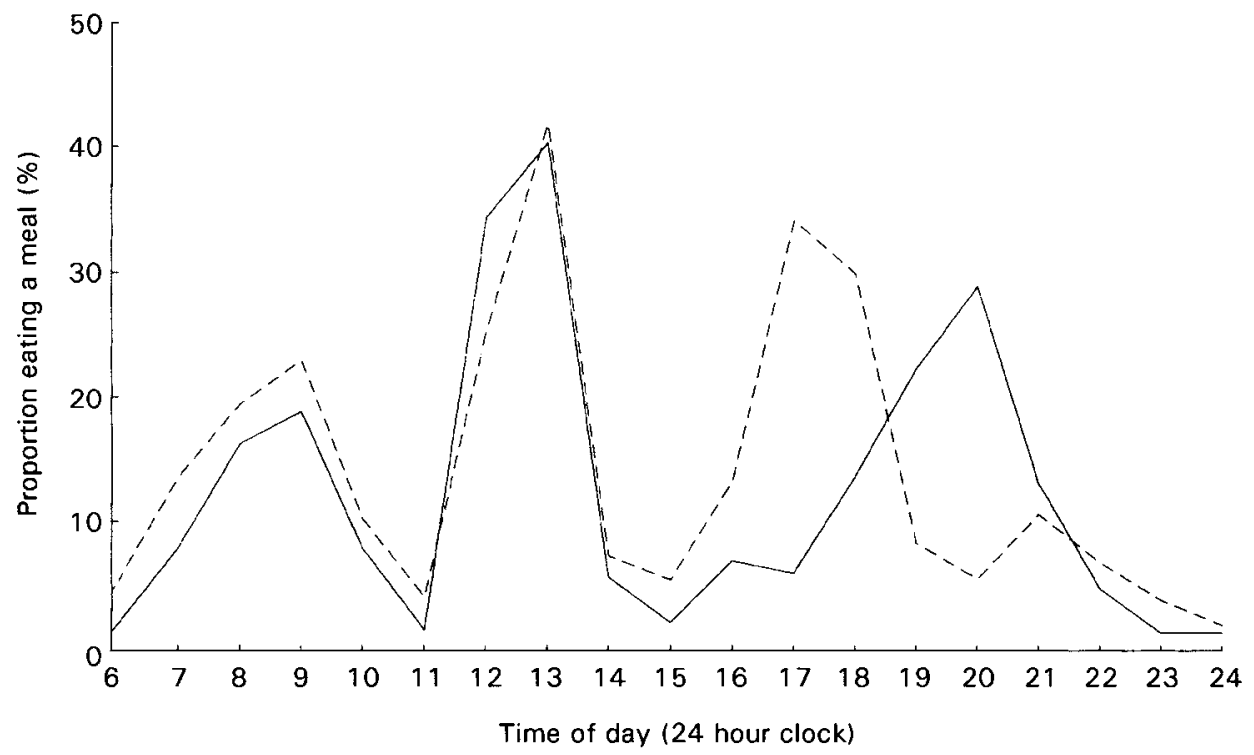

Fig. 1. Proportion of the study population eating a meal $v$. time of day for Europeans (---) and South Asians (-). 


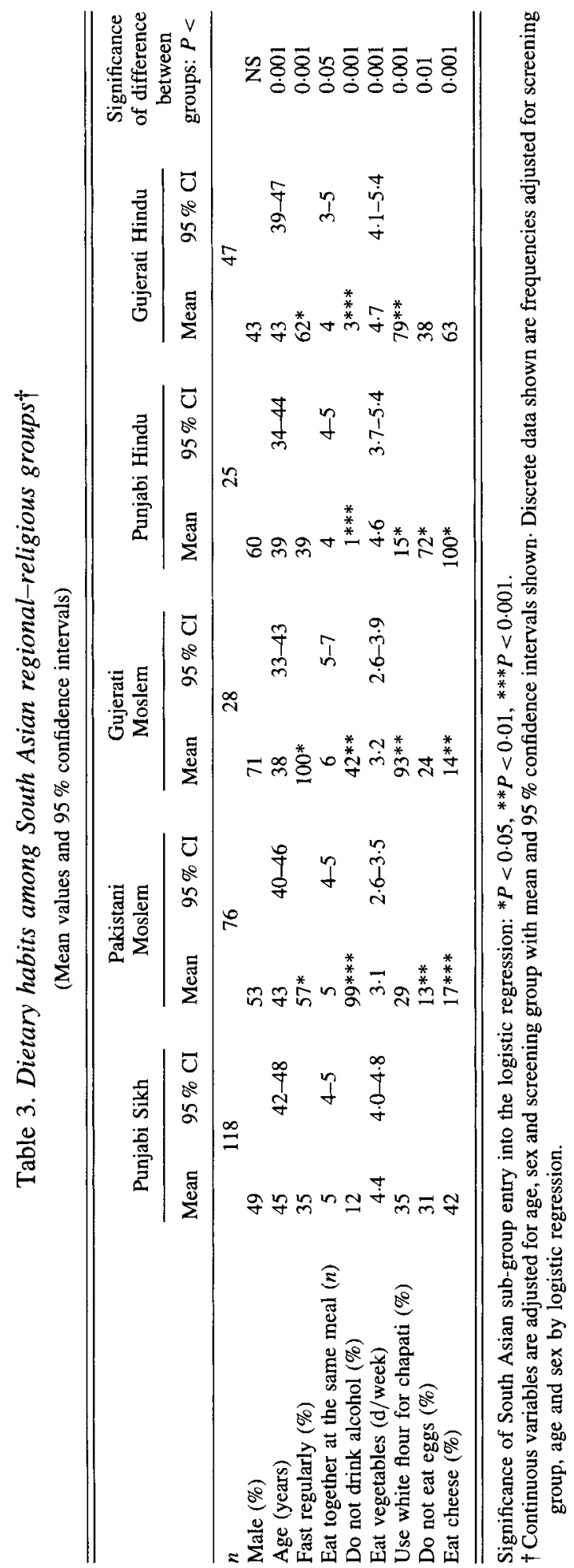


Table 4. Traditional dietary habits among South Asian regional-religious groups $†$

(Mean values and $95 \%$ confidence intervals)

\begin{tabular}{|c|c|c|c|c|c|c|}
\hline & Punjabi Sikh & $\begin{array}{c}\text { Pakistani } \\
\text { Moslem }\end{array}$ & $\begin{array}{l}\text { Gujerati } \\
\text { Moslem }\end{array}$ & $\begin{array}{c}\text { Punjabi } \\
\text { Hindu }\end{array}$ & $\begin{array}{c}\text { Gujerati } \\
\text { Hindu }\end{array}$ & $\begin{array}{l}\text { Overall signifi- } \\
\text { cance of differ- } \\
\text { ence between } \\
\text { groups: } P<\end{array}$ \\
\hline$n$ & 118 & 76 & 28 & 25 & 47 & \\
\hline $\begin{array}{l}\text { Use butter/ghee to } \\
\text { cook food (\%) }\end{array}$ & 66 & 93 & $21^{* *}$ & 36 & 47 & 0.001 \\
\hline $\begin{array}{l}\text { Use home-made } \\
\text { ghee }(\%)\end{array}$ & 20 & $5 * * *$ & 26 & 40 & 31 & 0.01 \\
\hline $\begin{array}{l}\text { Use home-made } \\
\text { yoghurt }(\%)\end{array}$ & 38 & $6 * * *$ & 25 & 72 & $68 *$ & 0.001 \\
\hline Eat paneer $(\%)$ & 18 & $8 * *$ & 8 & $100^{* * *}$ & $7 * *$ & 0.001 \\
\hline Eat paratha $(\%)$ & 16 & $8 * *$ & $4 * * *$ & $100^{* * *}$ & 11 & 0.001 \\
\hline $\begin{array}{l}\text { Eat dhal } \\
\text { (d/week) }\end{array}$ & $\begin{array}{c}3.5(95 \% \mathrm{CI} \\
3.1-3.9)\end{array}$ & $\begin{array}{l}1.8(95 \% \mathrm{CI} \\
1.5-2.2)\end{array}$ & $\begin{array}{c}2.0(95 \% \mathrm{CI} \\
1.5-2.5)\end{array}$ & $\begin{array}{c}3.6(95 \% \mathrm{CI} \\
2 \cdot 8-4.5)\end{array}$ & $\begin{array}{c}2 \cdot 7(95 \% \mathrm{CI} \\
2 \cdot 1-3 \cdot 2)\end{array}$ & 0.001 \\
\hline $\begin{array}{l}\text { Do not eat fish } \\
(\%)\end{array}$ & 10 & $4 * * *$ & 7 & 12 & $23^{* *}$ & 0.001 \\
\hline $\begin{array}{l}\text { Usually eat fried } \\
\text { fish (\%) }\end{array}$ & 20 & $34 *$ & $50 *$ & 22 & $6 * * *$ & 0.001 \\
\hline $\begin{array}{l}\text { Usually eat baked } \\
\text { fish (\%) }\end{array}$ & 6 & 4 & $12 *$ & $33 * * *$ & 4 & $0 \cdot 001$ \\
\hline $\begin{array}{l}\text { Usually eat } \\
\text { curried fish (\%) }\end{array}$ & 6 & 6 & $18^{* * *}$ & $15^{*}$ & 6 & 0.001 \\
\hline
\end{tabular}

Significance of South Asian group entry into the logistic regression $v$. Punjabi Sikh: $* P<0.05, * * P<0.01$, $* * * P<0.001$.

$\dagger$ Continuous variables are adjusted for age, sex and screening group with mean ( $95 \%$ confidence intervals) shown. Discrete data shown are frequencies adjusted for screening group, age and sex by logistic regression.

and least eaten by Moslems. There were no differences between South Asian groups in the types of milk used and a similar proportion as Europeans drank milk ( $9 v .15 \%$ respectively) and gold-top (Channel Island; $>4 \%$ fat) milk $(6 v .6 \%)$. South Asians were more likely to drink silver-top (whole; $>3 \%$ fat) milk (77 v. 63\%,P<0.001) and less likely to drink either skimmed ( $\leq 0.3 \%$ fat) or semi-skimmed $(1.5-1.8 \%$ fat $)$ milk $(12 v$. $19 \%, P<0.001$ ).

Punjabi Sikhs and Hindus ate dhal more frequently than Pakistani or Gujerati Moslems. Europeans were less likely than South Asians to eat dhal or pulses (49 v. $93 \%$, $P<0.001)$ but ate other vegetables more frequently $(4.9$ (95\% CI $4.6-5.2) v .4 .1(95 \% \mathrm{CI}$ 3.7-4.2) d/week). Pakistani and Gujerati Moslems ate vegetables less frequently than Sikhs or Punjabi or Gujerati Hindus. Europeans ate fruit less frequently than South Asians (21 v. $4 \%$ eating no fruit per week, $P<0.001 ; 3.5$ (95\% CI 3.1-3.8) v. 5.0 (95\% CI 4.5$5 \cdot 1) \mathrm{d} /$ week). There were no differences between South Asian groups. Yoghurt was eaten by $29 \%$ Europeans but $80 \%$ South Asians $(P<0.001)$. Indian sweets (e.g. burfi, jalebi, laddu) were eaten by $78 \%$ of South Asians with no South Asian group differences in the frequency of consumption (4 (95\% CI 4-5) d/week).

The degree of adoption of English food was comparable between South Asian groups, A similar proportion ( $46 \%$ ) had an English meal less than once weekly. There were no differences between South Asian groups in the proportion drinking coffee or eating chips, burgers, crisps or cake and/or sweet biscuits. However, in comparison with Europeans, fewer South Asians ate burgers (44v. $17 \%, P<0.001)$, chips $(79 v .74 \%, P<0.01)$ or cakes and/or sweet biscuits $(83 v .67 \%, P<0.01)$ or drank coffee $(75 v .53 \%, P<0.001)$. A similar proportion of South Asians ate crisps (58v. 64\%). 
There was no difference between South Asian groups in proportion eating English bread, although in comparison with Europeans, more South Asians ate no bread (1 v. 13\%, $P<0.001)$ and fewer ate wholemeal bread $(24 v .14 \%$; overall $P<0.001)$. South Asians used fewer artificial sweeteners $(10 v .6 \%, P<0.05)$ and ate less high-fibre breakfast cereal (e.g. bran) $(42$ v. $32 \%, P<0.05)$.

\section{DISCUSSION}

There appear to be four major influences on the foods consumed by South Asians: regional, religious, acculturation and health messages. The qualitative differences between the South Asian groups were similar to those previously described (Wharton et al. 1983). While South Asian groups in Foleshill clearly frequently ate high-fat food items (as found in other studies: Stephens et al. 1982; McKeigue et al. 1985; Peterson et al. 1986; Samanta et al. 1987; Miller et al. 1988), these were not just due to their traditional regional and religious practices. All groups had taken on English high-fat foods (e.g. chips, crisps, cake) and regularly had English meals. The qualitative health messages to reduce simple carbohydrate consumption and increase fibre intake had not been taken up by South Asians and few of them used artificial sweeteners, brown rice, wholemeal bread or ate a high-fibre breakfast cereal. While a high proportion of Europeans steamed and boiled their fish, few South Asians did so, preferring to have fried fish, although Gujerati Hindus also often had curried fish. The consumption of Indian sweets and fried snacks remained high.

Very few studies of domestic habits among South Asians have taken place. Clearly, much will have changed over the 7-year period that has lapsed and the habits in other communities are also likely to be different. However, the data are an adequate representation of the dietary habits of adults without diabetes in this community at the time of the survey. At the time of the study, the food frequency questionnaire used was not able to be validated against food diaries or other methods. All of these are prone to errors, but are now being increasingly used in studies (Block \& Hartman, 1989). Using the qualitative data reported here, it is difficult to explain the lower plasma triacylglycerol lower and total cholesterol concentrations previously described among Gujeratis (Simmons \& Powell, 1993). It is also hard to explain on the basis of diet the higher prevalence of NIDDM found in Gujerati Moslems (Simmons et al. 1992). The former could possibly be explained by a more quantitative analysis. The latter is unlikely to be due to dietary differences (Simmons et al. 1992). One of the other potential confounding factors with these data was the delay in the introduction of the questionnaire. The failure to find other differences between those attending in the first 10 months of the study and the later attenders (who did the dietary questionnaires), and the failure to demonstrate any dietary differences between those with and without NIDDM or IGT suggest that any bias was insignificant in comparison with the errors within the tool itself. Over-representation of households also had no major confounding effect. The relative excess of subjects who were 'screen positive' was adjusted for using multiple linear and logistic regression, although no diet-related variable actually had screening group as a significant entrant.

The Sorrento Maternity Hospital study suggested that men often did the shopping, while among Hindus and Sikhs, the women often did their own shopping (Wharton et al. 1983). This is in contrast with the current study where there were no differences in proportion of women doing the shopping in the different South Asian groups. Whether this is due to changes within the South Asian communities over the intervening years or whether these reflected differences between Birmingham and Coventry South Asians is unknown. South Asian men were not more likely to go shopping than European men. 
Among South Asians, cooking was more likely to be undertaken by a woman. In Europeans, the data from men and women were contradictory. European women reported that men rarely did the cooking, while men frequently said that they cooked. This may be due to the higher proportion of European women than men living away from their family and the higher proportion of European men than South Asian men living away from their family. The lower mean number of people eating together in European homes reflects the higher proportion of South Asians living with their family and the larger families that South Asians have.

While the dietary guidelines recommend three small meals per day (Peterson \& Govindji, 1988; British Diabetic Association, 1992), South Asian men and women had significantly fewer meals daily than this. South Asian women were also more likely to vary their meal times than Europeans. Such flexibility in South Asian meal times has been previously reported (Wharton et al. 1983). Whether this increases risk of morbidity or mortality is unclear; however, it does suggest that South Asians with newly diagnosed diabetes will have to make greater lifestyle changes than their European counterparts. This may result in conflict within the household and reduce the ability of the South Asian diabetic patient to adhere to the dietary recommendations for those with diabetes (Peterson \& Govindji, 1988; British Diabetic Association, 1992). The different times for major meals between Europeans and South Asians have not been previously reported. Any major media campaign attempting to emphasize healthy eating in the South Asian community would need to advertise at a later time than that for Europeans. Similarly, the different meal times for South Asians may require different insulin regimens or additional snacks to avoid hypoglycaemia before the evening meal. The problems associated with fasting among diabetic patients have been reported before (Chandalia et al. 1987).

In conclusion, South Asians in Foleshill consumed many high-fat food items with many cooking practices and foods adopted through acculturation. Health messages relating to the quality of nutrition had failed to penetrate the community, in spite of the amenability to change of many of the current customs. No comment can be made in relation to the quantities of food consumed. Improved tailoring of health messages to the domestic activities of South Asians as well as to the variety of religious and regional groups is most likely to assist the control of NIDDM in these populations.

We would like to thank the British Diabetic Association and Coventry City Council Community Programme team, Analox, Smith and Nephew, Beechams, Sherwood Medical, Becton Dickinson, Boehringer Mannheim, Nordisk and Eli Lilly for their support. We would also like to thank Dr T. D. R. Hockaday for support and Jo Farrington for dietetic advice. We are grateful to the Oxford Diabetes Trust for their support of the Sheikh Rashid Diabetes Unit. David Simmons was an Eli Lilly British Diabetes Association Research Fellow and the AMP Diabetes Research Fellow.

\section{REFERENCES}

Abraham, R., Campbell-Brown, M., Haines, A. P., North, W. R. S., Hainsworth, V. \& McFadyen, I. R. (1985). Diet during pregnancy in an Asian community in Britain - energy, protein, zinc, copper, fibre and calcium. Human Nutrition: Applied Nutrition 39A, 23-35.

Block, G. \& Hartman, A. M. (1989). Issues in reproducibility and validity of dietary studies. American Journal of Clinical Nutrition 50, 1133-1138.

British Diabetic Association (1992). Dietary recommendations for people with diabetes: an update for the 1990s. Diabetic Medicine 9, 189-202.

Chandalia, H. B., Bhargav, A. \& Kataria, V. (1987). Dietary pattern during Ramadan fasting and its effect on the metabolic control of diabetes. Practical Diabetes 4, 287-290. 
Elwood, P. C., Burr, M. L., Hole, E., Harrison, A., Morris, T. K., Wilson, C. I. D., Richardson, R. W. \& Shinton, N. K. (1972). Nutritional state of elderly Asian and English subjects in Coventry. Lancet 1, 1224-1227.

Jarman, B. (1983). Identification of underprivileged areas. British Medical Journal 286, 1705-1709.

McKeigue, P. M., Adelstein, A. M., Shipley, M. J., Riemersma, R. A., Marmot, M. G., Hunt, S. P., Butler, S. M. \& Turner, P. R. (1985). Diet and risk factors for coronary heart disease in Asians in Northwest London. Lancet 2, 1086-1090.

Miller, G. J., Kotecha, S., Wilkinson, W. H., Wilkes, H., Stirling, Y., Sanders, T. A. B., Broadhurst, A., Allison, J. \& Meade, T. W. (1988). Dietary and other characteristics relevant for coronary heart disease in men of Indian, West Indian and European descent in London. Atherosclerosis 70, 63-72.

Peterson, D. B., Dattani, J. T., Baylis, J. M. \& Jepson, E. M. (1986). Dietary practices of Asian diabetics. British Medical Journal 292, 170-171.

Peterson, D. \& Govindji, A. (1988). Giving dietary advice to Asian diabetic patients. Diabetic Medicine 57, 683-686.

Samanta, A., Campbell, J. E., Spalding, D. L., Panja, K. K., Neogi, S. K. \& Burden, A. C. (1987). Dietary habits of Asian diabetics in a general practice clinic. Human Nutrition: Applied Nutrition 41A, 160-163.

Simmons, D. \& Powell, M. J. (1993). Metabolic and clinical characteristics of South Asians and Europeans in Coventry. Diabetic Medicine 10, 751-758.

Simmons, D., Powell, M. J. \& Williams, D. R. R. (1989). Prevalence of diagnosed and previously unknown diabetes in a predominantly Asian community: preliminary findings of the Coventry Diabetes Study. British Medical Journal 298, 18-21.

Simmons, D., Williams, D. R. R. \& Powell, M. J. (1992). Prevalence of diabetes in different regional and religious South Asian communities in Coventry. Diabetic Medicine 9, 428-431.

Stephens, W. P., Klimiuk, P. S., Warrington, S. \& Taylor, J. L. (1982). Observations on the dietary practices of Asians in the United Kingdom. Human Nutrition: Applied Nutrition 36A, 438-444.

Ward, R. J., Abraham, R., McFadyen, I. R., Haines, I. D., North, W. R. S., Patel, M. \& Bhatt, R. V. (1988). Assessment of trace metal intake and status in a Gujerati pregnant Asian population and their influence on the outcome of pregnancy. British Journal of Obstetrics and Gynaecology 95, 676-682.

Wharton, B. A., Eaton, P. M. \& Day, K. C. (1983). Sorrento Asian food tables: food tables, recipes and customs of mothers attending Sorrento Maternity Hospital, Birmingham, England. Human Nutrition: Applied Nutrition 37A, 378-402.

World Health Organization (1985). Diabetes Mellitus: Report of a WHO Study Group. Technical Report Series no. 727. Geneva: WHO. 